\title{
Why We Must Raise the Age of Juveniles: A Scientific Review
}

\author{
Avital Mintz ${ }^{1}$ and Julian Day-Cooney" ${ }^{1 \#}$ \\ ${ }^{1}$ Trinity School, New York, NY, USA \\ \#Advisor
}

$\underline{\text { ABSTRACT }}$

Since 1971, the age at which people are no longer considered juveniles in the eyes of the law has been 18 years old. However, given that 18-25-year-olds have the highest rate of crime of all age groups, it is clear that prison is not working well to prevent future crimes of this specific group; The system in place is failing these ages. Neuroscience evidence has proven that the brain is still maturing after 18 years-old, especially in brain regions related to criminal behavior and instincts. In this paper, using evidence from neuroscience, I propose that the age of adulthood in the courtroom must be revised to reflect new discoveries in brain science.

\section{Introduction}

America's juvenile justice system seems to have progressed little since the 19th century. Until the 1800s, regardless of the age, criminals were held in jail. There was no separation or distinction of youth and adult offenders. Juveniles of all ages were confined in prisons filled with adult criminals.[1] In 1815, the Reverend Thomas Eddy began to raise awareness on the adverse effects of integrating youth with older criminals.[2] His work eventually led to the establishment of the New York House of Refuge in 1825. This institution housed countless youth deemed to be criminal.[3] By the 1840s, more than twenty facilities similar to the House of Refuge were open. These houses were used as an alternative to jail in an attempt to separate minors and adults. However, while these houses were progressive for the juvenile justice system, youth were still tried in adult courts. In 1899, however, the first juvenile court was opened in Chicago.[4] There were two main principles in the establishment of the court: juveniles were not as culpable for their crimes as adults and that their potential to be rehabilitated was much greater than that of adults.[5] Years later, as countless juvenile courts were established, these two standards held true.

Although the age at which offenders are considered juveniles differs from state to state, most states' age threshold is 18 years old (for a few, it is as low as 16). The age at which people are considered adults used to be 21. When World War II came, the government needed more young men to be drafted, leading to the switch of the minimum age of soldiers from 21 to 18. Citizens found it ridiculous that young people were forced to fight without having the rights of an adult, such as voting. In response, the United States lowered the voting age (and, therefore, the idea of who an adult is) to 18 in 1971.[6] The United States adopted 18 as the universal age of adulthood.

The lowering of this age was--and still is--negatively impactful on youth. In particular, juvenile court proceedings are focused on rehabilitation rather than punishment and are more lenient in an offender's appropriate punishment. However, there are many situations in which a minor's juvenile status is ignored in the eyes of the court. All states have transfer laws that authorize youth to be prosecuted as adults for serious and violent offenses.[7] In most situations, the decision of how an offender will be tried depends on the judge. In addition, there are many racial biases in the handing out of "adult" status. For example, in Florida, despite black youth making up around half of juveniles arrested, two-thirds of minors transferred to adult court are black.[8]Additionally, America is the only country in the world that authorizes youth to be sentenced to life without parole, an extremely inhumane punishment that is not meant for true rehabilitation of a criminal.[9] Although there have been several Supreme Court cases which opposed 
sending a child to jail for life without parole in certain circumstances, it is still up to the judge if a juvenile guilty of homicide will be sentenced to life without parole. A judge is, therefore, often expected to answer the question of whether this offender as culpable for their crime as an adult. However, this can be considered a scientific question.

Instead of using scientific data, judges base their determination on intuition, which is inevitably biased. Although there has been progress in some aspects of the criminal justice system, the juvenile justice branch mirrors closely what it was in the 20th century in how it treats minors. However, since the 1800s, new research has shed light on the science of brain development and how the brain changes into an "adult" brain. Many scientists in the present time can confidently say that 18 is too young to be held as culpable for a crime you committed as adults are. The legal system should place value in science, rather than human instinct. The advancements in neuroscience have increased our understanding of maturation in the brain.

Scientists have evidence from many different metrics that can give insight into how mature someone is. Therefore, using this knowledge, can we quantify human maturity from a scientific lens in order to better determine the age of adulthood in court?

\section{Science of Maturity}

\section{Previous Uses of Neuroscience to Examine Culpability}

The criminal justice system is not foreign to using neuroscience in the courtroom. In the juvenile justice system in particular, neuroscience has been the foundation of evidence for several legal precedents. In understanding the application of brain science in juvenile law, it is crucial to understand what "cruel and unusual punishment" means and how it is applied. The Eighth Amendment in the United States Constitution states that, "Excessive bail shall not be required, nor excessive fines imposed, nor cruel and unusual punishments inflicted."[10] Cruel and unusual punishments convey that a certain legal sentencing is inhumane and too severe given the crime committed. However, the legal system differentiates between physical harm and emotional harm of a citizen, "with emotional harm being treated as a second-class citizen."[11] Since physical harm is more evident and obvious, courts have been quick to disregard mental harm punishments have on offenders. Yet, as science has progressed, neuroscientific evidence that provides tangible evidence for emotional harm has as well. Science is now able to reveal when the punishment is mentally damaging. Throughout the 20th and 21st century, therefore, the justice system has used brain science in characterizing certain punishments as cruel and unusual, especially for minors. Although the law makes the final verdict as to what punishments should be allowed and the treatment of juveniles, science provides a framework to understanding the adolescent mind and therefore what is most beneficial to youth.[12] It is important to note the past juvenile offender cases for which neuroscience was used in the verdict in an effort to understand how critical brain science is for youth legal cases and therefore to the future of the juvenile justice system. The most notable example of the Supreme Court acknowledging the science of teenage brain development is Roper v. Simmons.

Roper v. Simmons laid the foundation for scientific evidence to support the notion that juveniles must be treated differently than adults. In 1993, Christopher Simmons, at the age of 17, planned and committed a vicious killing of a woman whose house he broke into along with a 15- year-old. The murder was considered a capital offense-the nature of the attack was violent and brutal.[13] Once Simmons turned 18, he was sentenced to death. In response to this ruling, he moved to set aside the sentencing as a result of inadequate attorneys who failed to use his age, and therefore his lack of impulse control and distinct morals, as evidence. However, the motion was rejected, and Simmons appealed. As this case proceeded to be appealed, the death sentence was maintained. Amidst the continuous appeals, the 2002 Supreme Court case Atkins v. Virginia, where the court ruled that it is a cruel and unusual punishment to execute people with intellectual disabilities.[14] This ruling suggested that only those who could be held completely blameworthy should be executed. Using this ruling Simmons attorneys argued that as a juvenile, his brain was not fully developed similar to those with intellectual disabilities and, therefore, it is unconstitutional to sentence him to 
death. He was successful in this conviction; the Supreme Court of Missouri decided that executing juvenile offenders was cruel and unusual, thus not legal. The opinion of the court states, “Once juveniles' diminished culpability is recognized, it is evident that neither of the two penological justifications for the death penalty- retribution and deterrence of capital crimes by prospective offenders, e.g., Atkins, 536 U. S., at 319_provides adequate justification for imposing that penalty on juveniles."[15] Justice Kennedy of the Supreme Court writes, "[the death sentence] is not proportional if the law's most severe penalty is imposed on one whose culpability or blameworthiness is diminished, to a substantial degree, by reason of youth and immaturity."'[16] Judges took into account the lack of maturity seen in juvenile brains. Simmons was sentenced to life in prison without parole. This was the first important decision-of many--that took in consideration immaturity backed by brain data in youth.

In Graham v. Florida, punishments that were considered under the law cruel and unusual for juveniles widened. At 16, in 2003, Terrence Jamar Graham pleaded guilty and spent a year in jail for attempted armed burglary with assault or battery. Less than six months later, Graham was arrested for armed home invasion and robbery, violating his probation from his robbery sentencing.[17] The judge ruled that Graham had the most extreme punishment, which, as a result of Roper v. Simmons, was sentenced to life in prison without parole. However, after many appeals, the case reached the Supreme Court. The court ruled that " $[\mathrm{t}]$ he Constitution prohibits the imposition of a life without parole sentence on a juvenile offender who did not commit homicide."[18] Using testimonies of neuroscientists, the court noted that "the limited culpability of such offenders and the severity of these sentences all lead the Court to conclude that the sentencing practice at issue is cruel and unusual."[19] Graham was resentenced to 25 years in prison. This case set precedent for using the scientific evidence of juveniles' brains to prove they are more likely to be rehabilitated, and therefore, only youth who committed murder should be sentenced to life in prison without parole. Justice Kennedy writes, "[life imprisonment without parole] is not appropriate in light of a juvenile nonhomicide offender's capacity for change and limited moral culpability. A State's rejection of rehabilitation, moreover, goes beyond a mere expressive judgment. As one amicus notes, defendants serving life without parole sentences are often denied access to vocational training and other rehabilitative services that are available to other inmates...For juvenile offenders, who are most in need of and receptive to rehabilitation...the absence of rehabilitative opportunities or treatment makes the disproportionality of the sentence all the more evident."[20] Imposing life-long punishments with no chance of parole on youth is cruel and unusual since juvenile's brains have a greater capacity to be rehabilitated than adults, and future cases would also come to prove the lack of culpability in juveniles.

Miller v. Alabama set legal precedent for the court's acknowledgment of juvenile's diminished culpability compared to adults. Only two years after the court ruled on Graham v. Florida, the Supreme Court issued a ruling to an appeal that was a consolidation of two juvenile offenders.[21] In 1999, Kuntrell Jackson, a 14-year-old living in Arkansas, waited outside a video game store as two teenagers committed an attempted armed robbery that led to a murder of store clerk. Although he was not the one holding the gun, Jackson was tried as an adult and convicted of capital murder. The court sentenced him to mandatory life in prison without parole. Although he appealed to the ruling, the Arkansas Supreme Court supported the ruling. Four years after Jackson's crime in Alabama, Evan Miller, as a 14year-old, along with another teen, brutally beat a man to death. The evidence was clear in proving Miller's guilt, and after his case was transferred to adult court, the jury was quick to convict him of murder. Three years later, he was sentenced to life without the possibility of parole. After an appeal, the Alabama Court of Criminal Appeals claimed this punishment was not cruel and unusual given how violent and barbaric Miller's offences were. The two cases, which were handled similarly in the eyes of the law, were consolidated and presented to the Supreme Court and referred to as Miller v. Alabama. Recognizing the extensive evidence and testimonies that youth are not as culpable for their crimes as adults, the court concluded that mandatory life sentences without the possibility of parole for all criminals under 18 were a direct violation of the Eighth Amendment and therefore was illegal. This case recognized that all juveniles, regardless of the nature of their crime, must be treated differently than adult offenders. Justice Kagan writes, "Our decisions rested not only on common sense_on what "any parent knows"_but on science and social science as well... We reasoned that those findings_ of transient rashness, proclivity for risk, and inability to assess consequences - both lessened a child's 'moral culpability' and enhanced the prospect that, as the years go by and 
neurological development occurs, his 'deficiencies will be reformed."'[22] Miller v. Alabama emphasized that regardless of the nature of a crime committed by a juvenile, a youth's culpability differs from that of adults.

When contrasting cases where neuroscience succeeded and failed in the courtroom, it becomes clear that while the justice system will use science evidence as demonstrated in these cases, it also neglects certain pieces of evidence that call into question the age of adulthood being set to 18. An infamous case that reflects failure in the use of scientific evidence is that of Dzhokhar Tsarnaev. At 19, Tsarnaev played a crucial role in the Boston Marathon bombing in 2013, "one of the worst domestic terrorist attacks since the 9/11 atrocities."[23] The proof against him was obvious, and he admitted to all 30 accusations that the government alleged. The jury recommended a death sentence for him. In response, Tsarnaev's attorneys "cit[ed] Roper v. Simmons... and concede[d]... that the Supreme Court has 'dr[awn] a bright line' for death eligibility 'at age 18." They continued that, "the factors Roper considered relevant in granting death-penalty immunity to persons under 18 .... apply equally to persons under 21 . Looking for support, [they] argue[d] that 'scientific research' since Roper 'has explained the effects of brain maturation, or the lack thereof, on the behavioral and decision-making abilities of late adolescents in their late teens and early twenties." "[24] However, the government was "unimpressed," stating that there was "no research about "brain maturation that is substantially different from the research available' at the time Roper came down." Their justification for not accepting this neurological evidence demonstrating the similarities in brain development between under- and over18-year-old make the cutoff at 18 extremely arbitrary. It was not that the evidence was inadmissible or misleading, but that this research was present during Roper, yet the decision only included those under 18. It seems that although they focused on neuroscience evidence for cases of minors, they valued precedent over the developing scientific field for offenders considered adults.

It is crucial to recognize that in these cases, the judges seem to pick 18 as the arbitrary cutoff of when an offender is considered a juvenile. There is no evidence that they cited those points directly to 18 being the age a brain is mature enough to be fully culpable. If anything, the evidence that proves "adults" just over the age of 18 is still too young to be considered an adult is neglected, such as in the case of Dzhokhar Tsarnaev.

Additionally, in Roper v. Simmons, the judges handpicked their data, ignoring essential components of the evidence. The Opinion of the Court cited evidence from Jeffrey Arnett's Reckless Behavior in Adolescence: A Developmental Perspective [25] in proving that youth under 18 are not as culpable as adults. However, in that same paper, Arnett writes as a framework for his evidence that the court cites, "Adolescence will be discussed here as extending from puberty to the early 20's." Nevertheless, the court only applied his evidence for those under 18 , neglecting that it is applicable for people up to early twenties. Similarly, in Graham v. Florida, the Opinion of the Court cites evidence from the Brief for J. Lawrence Aber et al. as Amici Curiae 28-31.[26] This is a crucial piece of evidence as the Court made their ruling based on juveniles' capacity to be rehabilitated. However, this opinion states, in evidence of adolescents being less mature than adults and more capable of rehabilitation, "...the frontal lobes continue to develop...from early adolescence through a person's early twenties." [27] Nevertheless, as with Roper, the Court uses this evidence only for offenders under 18. They do not take into account that the exact reasoning they use about brain development holds true for those above 18. Once again, the pattern of neglecting specific parts of evidence in the Court holds true in Miller v. Alabama. A majority of the evidence used in the Opinion of the Court for this case was quoted from Roper v. Simmons, which, as mentioned before, came from evidence that a brain is still maturing until someone's twenties.

What seems to be inconsistent use of scientific evidence (essentially, cherry picked data) should be taken more seriously. People are suffering--whether that be in death, cruel treatment, or a lack of rehabilitation even if they are capable of recovery. The legal system has shown that they can use neuroscience evidence for juvenile cases. Not only have these Supreme Court cases banned death penalties and life without parole sentences for juveniles, but they have set a precedent for the consideration and even acceptance of neuroscience in the courtroom. It is clear that it is plausible to prove a punishment to be cruel and unusual with scientific evidence. What is stopping them from reexamining neuroscience from a broader lens in an effort to allow science to lead the way to a change in the criminal justice system for young adults? 


\section{Behavioral Evidence of Immaturity}

Psychology has been studying behavioral correlates to criminality for decades. One study, for example, measured selfcontrol using the ultimatum game (UG).[28] Self-control plays a large role in criminal behavior as a lack of it may drive a person to committing acts without thinking through the consequences and dangers. In UG, two anonymous subjects, one a "proposer" and the other a "responder" have to agree on how they will divide a given amount of money. The proposer makes only one suggestion on how the money should be allocated between the two subjects. The responder may accept or reject this offer. If they accept the amount of cash that is allocated to them, each player receives this money. On the other hand, if they reject the offer, neither receive money. The decision is based on whether equity drives the subject or economic self-interest. Players must use self-control to balance their feelings of economic interest and fairness of allocation of the money. Another study interviewed and questioned subjects ranging in age from 1030.[29] Researchers found that, after gauging maturity by "impulse control, sensation-seeking, resistance to peer pressure, risk perception, and awareness of long-term consequences" [30], emotional maturity is not attained until after 22 years of age.

This study is one of many in which psychologists use their observations to understand behavior. However, we can quantify and improve the accuracy of experiments like these, where characteristics relating to criminal behavior are tested, using neuroscience. More specifically, we can use neuroscience to map more precisely our brain at certain ages to show us that we are still developing into our twenties.

\section{Anatomical Evidence of the Brain's Lack of Maturity After 18}

The evidence that the brain is maturing after someone is 18 is not enough in itself; how brain maturity level relates to behavior is also very important. In this section, evidence for anatomical immaturity will be presented in tandem with the functional implications for that lack of maturity. It has been known for some time that critical developmental stages finish in the early- to mid-twenties.[31] There are many different factors that contribute to brain maturation. For example, one major component is the pruning of the neurons.[32] Neurons are the essential units of the brain. The pruning of neurons refers to the elimination of unnecessary connections in the brain. The neurons that are pruned are spread throughout the human central nervous system and are referred to as gray matter.[33] In 2017, Gennatas et al. [34] collected data on changes in gray matter volume (GMV) during adolescence. 1189 subjects, between the ages of 8 and 23, were selected for this study. The scientists used an MRI scanner to quantify the amount of gray matter in the brains of the participants. To ensure accuracy, scientists separated the data by sex assigned as birth, since studies have shown that both sexes differentiate in neurotypical functions and anatomy.[30] In figure 2, the decrease in gray matter as age increases is represented. The blue line on the graph represents the male data and the red line represents female data. The relative percent is each data point relative to the largest gray matter volume, which was males at the age of 8. In this method, they are able to compare GMV in relation to the ratio, as opposed to quantities; this is known as using relative percentage. The $y$-axis is the relative percentage of gray matter volume, and the $\mathrm{x}$-axis represents the ages in years, which range from 18-23. The shaded bands correspond to the 2 percent standard error of the fit line in their data. 


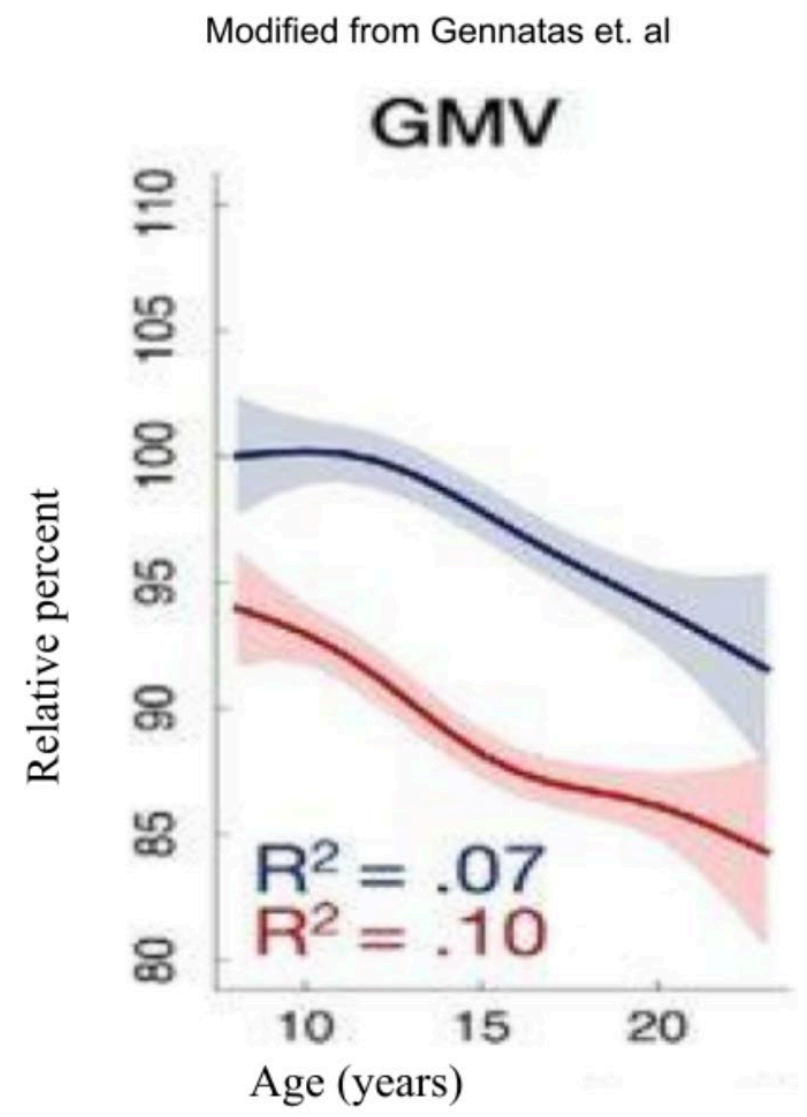

Figure 1. Gray matter volume decreases in both females and males as age increases. The relative percent is defined as the fitted value for males at age 8 . The shaded bands correspond to the 2 percent standard error the line-best-fit.

This representation of decrease in gray matters suggests that as age increases, the connections in the brain become more efficient and unnecessary ones are pruned, therefore making way for more efficient connections. There are still changes into someone's 20s, for both men and women. Several studies have proven that as GMV decreases, impulse behavior improves.[35] Connection efficiency is a marker of maturity since it helps with complex cognitive processes.[36]

Another factor that contributes to connection efficiency is white matter--the tissue that lies beneath the gray matter area.[37] Gray matter is spread throughout cables that carry signals between the neuronal cell bodies, known as axons. Axons can be converted in a type of fatty acid, myelinan, that helps connections move quickly and adeptly. Myelinated axons act as a messenger between different brain regions. All of a brain's regions are connected by white matter tracts. White matter ensures the efficiency of information processing, which allows us to do everything from focus on a task to make informed decisions. Therefore, the development of white matter can be a marker of maturity and a reason for someone's criminal acts. Tamnes et. al [38] conducted research in which the changes in white matter (WM) volume and structure were studied. With 168 participants ranging in ages from 8-30 years old, researchers used an MRI technique called diffusion tensor imaging to measure white matter volume in different brain regions. The results were clear; for all brain regions they studied, there was a positive relationship between age and white matter volume. Figure 2 shows five different brain regions and the WM development that coincides with them. Although each region functions differently, WM connects each one. Therefore, it is unnecessary to examine each on its own since they all communicate and work together. The $y$-axis represents the WM volume relative to the mean total volume in all participants (i.e., the "z-score") and the x-axis shows the age of the participants in years. This clearly shows that WM volume does not reach full potential at 18 , but instead the volume is still increasing. 
Modified from Tamnes et. al
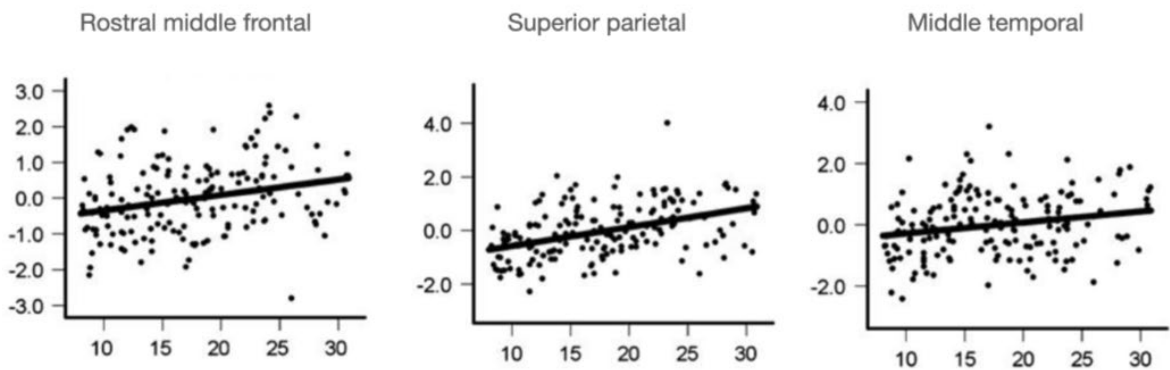

Medial orbitofrontal

Isthmus cingulate
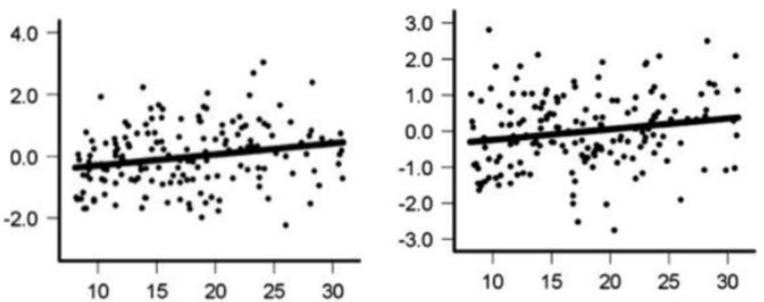

Figure 2. The graph shows z-scores of white matter by ages (years). Z-scores represent the WM volume relative to the mean total volume in that specific brain region of all participants.

Given this evidence, WM volume is not close to being at its full potential at 18. An 18-year-old's brain, for example, may have slower connections in specific brain regions related to criminal behavior, which potentially could result in an increase of offenses or the affinity for immoral behavior.

Another important method to understand brain maturity is diffusion tensor imaging (DTI). DTI is a method that uses individual brain voxels--a $3 d$ pixel--to measure the average water movement across the brain.[39] This method helps determine the anatomy of a brain network because scientists can infer that since there is water movement in a particular area, there are axons going through that region. DTI can help visualize and quantify how many projections-- axons-- there are between certain brain regions, therefore informing us on how connected two regions are.

Swartz et. al[40] used this method to understand the changes with age in the connections between the prefrontal cortex and the amygdala. The amygdala is critical in the process of maturation. Studies have shown that lesions in the amygdala lead to impairments and abnormalities in emotional behavior.[41] For example, it's harder to recognize visual signals on a person's face that convey emotional significance in social settings[42] when the amygdala is not functioning properly. A manifestation of this lesion, for example, is not being able to conclude how people are feeling based on their facial expressions--whether they are happy, sad, angry, or another emotion. Scientists have been able to define the amygdala, with evidence from lesion studies, as the function where your brain wants to let anxiety, fear, and anger, guide your actions. On the other hand, the prefrontal cortex, another region important to maturity of the brain, is the brain's "rational part"[43] and is often referred to as the maturity "center". Research has shown that self-control is often diminished for people who have lesions in their prefrontal cortex, therefore supporting the PFC as an impulse control mechanism. The amygdala and PFC play crucial roles in criminal behavior. Similar to Gee et. al's study [44], participants (ages 9-19) were shown different emotional faces.[45] Uncinate fasciculus is a white matter tract--areas that are mainly made up of myelinated axons--that connects different parts of the brain, including the amygdala and prefrontal cortex. They found that there was a negative relationship between left uncinate fasciculus FA and left amygdala activation (to both happy and sad faces). This negative relationship implies that when the 
amygdala is activated more, there is a smaller FA value of uncinate fasciculus. A smaller FA value implies a stronger connectivity between brain regions since there are less barriers in the white matter tract. Because this white matter tract connects the amygdala and prefrontal cortex, when there are less barriers for molecules to move through, the connectivity is strengthened and improved. This relationship is important while analyzing another piece of data from this study. They found that between the ages of 8 and 20 years old, the older a participant was, the left amygdala activation was lower. If we take this relationship that amygdala activity decreases with age, then, using the FA and amygdala activation negative relationship, suggests that as age increases, since amygdala activation decreases, uncinate fasciculus FA does as well. This implies that as age increases, there are less barriers between brain regions and there is stronger connectivity between the prefrontal cortex and the amygdala. Although with age there is stronger connectivity, these connections may be inhibitory ones, where the PFC is regulating the amygdala and the heightened emotions. Regardless of the nature of connections, this study made clear that age is an important factor in the crucial connection of these two brain regions and it is still improving in efficiency after 18 years.

Although the evidence that the brain is anatomically developing past 18 is strong, it is not always enough in proving that the brain is still maturing after 18. Rather, if we look at functional data, we can see how specific brain regions are responding and communicating during someone's behavior and actions.

\section{Prefrontal Cortex and the Amygdala Functional Connectivity Evidence}

The prefrontal cortex and the amygdala, specifically the connection between the two functions, are crucial components in the nature of a human's behavior. There has been abundant evidence that during emotion regulation, there is significant interaction between the amygdala and PFC.[46] Emotion regulation is an ability that many criminals may lack; without this skill, it is more likely that you act on your emotions and therefore, commit unlawful acts. To understand emotion regulation throughout adolescence, Gee et al.[47] conducted a study called A Developmental Shift from Positive to Negative Connectivity in Human Amygdala-Prefrontal Circuitry. With forty-five physically and psychologically healthy participants, whose ages ranged from 5-22, the researchers took several noninvasive imaging scans that measure brain activity (known as functional magnetic resonance imaging) while people observed different emotional (happy, fearful, neutral) faces that were shown in small increments of time. Emotional faces have been used in past studies to engage the amygdala and therefore, they (successfully) expected that showing these faces would incite activity in the amygdala of participants. To quantify the connection between the amygdala and the PFC, they used psychophysiological interactions, or PPI. PPI is a method for scientists to investigate relationships between different brain areas.[48] They used this method to identify the extent to which the amygdala was functionally connected to other brain regions. After gathering the data, researchers noted that the only age-related change in connectivity with the amygdala was the medial prefrontal cortex. Their data suggested that as age increases, the correlation between the two regions decreases. In addition to the negative relationship, the connection between the regions shifted from positive to negative as age increased. In figure 3 , the black line represents the line of best fit, representing the negative relationship. 


\section{Modified from Gee et. al}

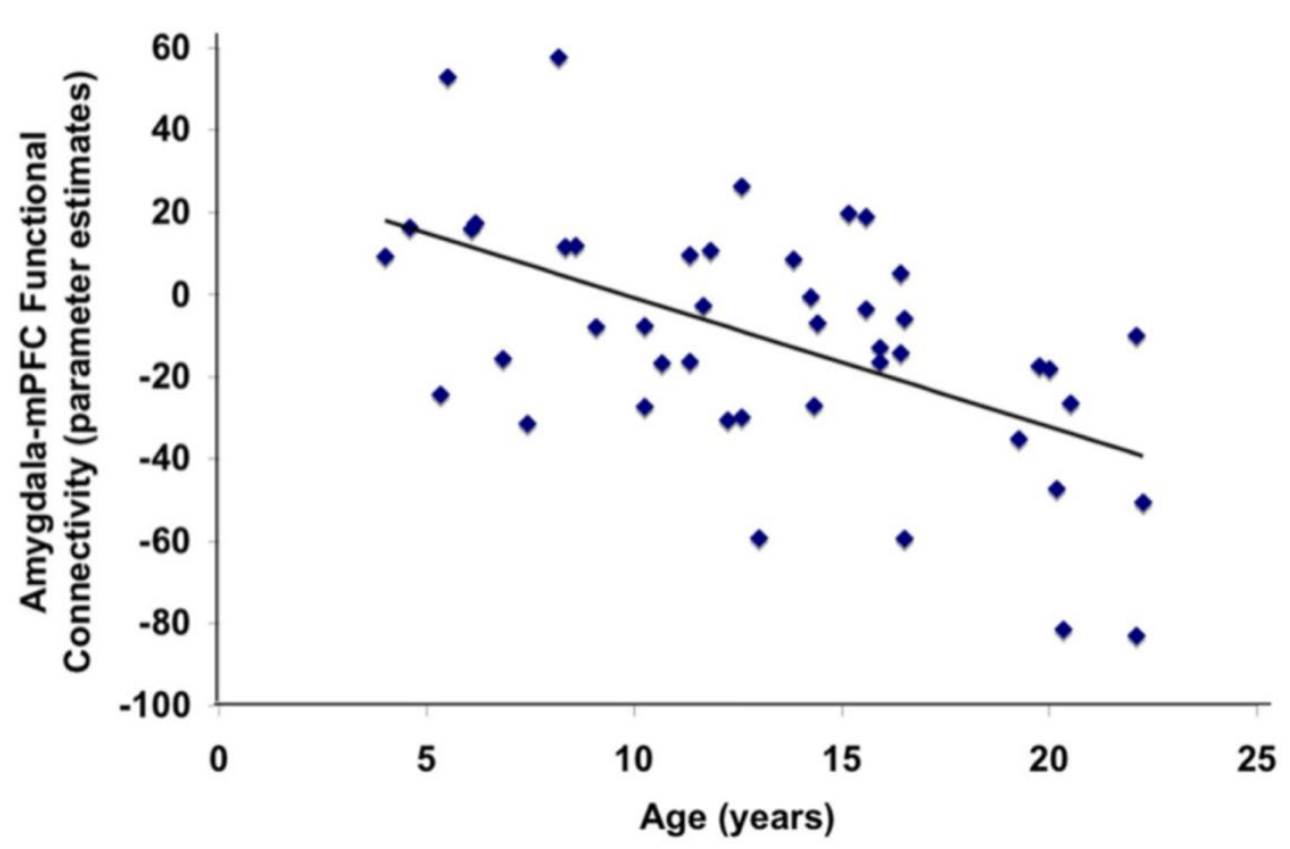

Figure 3. Graph of Amygdala-medial PFC functional connectivity as a function of age

The implication of this conclusion is that when one function is active, the other is inhibited. In other words, when the brain is more mature, there is anti-correlation--as age increases, connectivity between these regions decreases--between the amygdala and medial prefrontal cortex. The initially positive relationship between neurons in the two brain areas implies that the amygdala governs early-on what the prefrontal cortex is doing. This can be seen in the behavior of young children: they are more likely to act on their emotions, even if it is not rational or sensible. It is clear that the amygdala, an emotional center, has control and connection over the PFC and their impulse control has yet to be developed. Although at 18 , when someone is legally mature, the relationship is negatively correlated, but it is still not as negatively correlated as that of early- and mid-twenty-year-olds. This suggests that in later ages, heightened emotions have less control over actions than they do at 18--that is, the prefrontal cortex is not as influenced by emotions as it is in a younger brain. This piece of evidence is crucial in understanding just why 18 -year-olds should not be considered adults. It shows that even at 22, connectivity is still changing and decreasing between the PFC and amygdala. Twenty-year-olds are still susceptible to letting their emotions guide their actions, and therefore, can be more likely to commit acts that may not be rational.

All of these neuroscientific studies, done with different methods and participants, support the idea that the connection between amygdala and the prefrontal cortex is not done developing at 18 . Therefore, it is not scientifically just to define 18-year-olds, or even twenty-year-old's, as mature as those older than them.

\section{Ethical Implications of Changing the Age of Adults}

Given the scientific evidence against this age of adulthood, it seems to be that the legal system has chosen an arbitrary number for juveniles to be considered an adult; However, the weight of this seemingly artificial consensus is heavy. In 2011, over 200,000 18-24-year-olds were in adult prisons.[49] The highest rate for victimization--violence and cruelty at the hands of fellow prisoners and guards--of all ages in states/federal prisons is 18-20-year-olds. In addition, 
a study done by the Bureau of Justice showed that 18-24-year-olds who had been imprisoned with adults had the highest rate of recidivism 75.4 percent.[50] In juvenile detention centers, the focus is rehabilitation. Youth correctional facilities use therapies designed to improve behavior and decision making. Treatment programs for young offenders have reduced recidivism by as much as 40\%.[51] On the other hand, adult prisons tend to use punishment as prison's main function.

Clearly, given the extremely high rate of recidivism for 18-24-year-olds, the prison system is failing. In adult prison, an offender who is in that age range is surrounded by older, often more violent people. As discussed in this paper, the connections in people between 18 and mid twenties' brains are not fully developed. Their emotions have more control over their actions than that of adults, and they may react badly to their harsh surroundings (prison). Their brain anatomy--the connections, gray matter, and more--seem to be more similar to that of juveniles than adults given the potential development that is still occurring in the brain. Therefore, it is fair to use statistics for juveniles to get a better understanding, although not perfectly accurate, of 18- mid twenty-year-olds. A 2007 report done by the Campaign for Youth Justice found that juveniles in adult prisons are 36 times more likely to commit suicide than youth in juvenile detention centers.[52] This statistic in itself reflects how unequipped and inadequate adult prisons are for people whose brain is not fully developed and for those who have trouble regulating their emotions. It is clear that adult prisons are more violent and less effective for youth. Given that adolescents over 18 have a brain that is not fully developed and still has connections to be formed, we should air on the side of caution. The ethical faults are great if we imprison these people in an adult jail. They won't have the help their changing brain needs to change their behavior. The moral and scientifically backed decision would be to raise the age at which juveniles can be imprisoned in youth detention centers.

\section{Discussion}

Neuroscience has been used to alleviate the suffering of those under 18, but not raising the age at which people are no longer considered juveniles. The American legal system has not strayed away from using neuroscience in their rulings. For example, in Roper v. Simmons, Graham v. Florida, and Miller v. Alabama, neuroscientific evidence was used in setting precedents for future cases and for the judges' decisions. However, the evidence has been cherry picked; often courts only use evidence that is necessary for their argument, neglecting evidence that may change legal precedents. The legal system has shown they are not afraid to use neuroscience in cases. Therefore, there should be nothing stopping them from using clear evidence that 18 years should not be the age at which people are considered an adult.

Defining someone as an adult implies their brain is mature and developed. However, there is copious amounts of evidence indicating that 18-year-olds and older are not done with brain development. For example, one clear-cut proof is that of gray matter. Gray matter is the tissue that helps process information in the brain. Yet, as age increases, through pruning, gray matter increases in efficiency of its connections and therefore, brain functions. Research has shown that gray matter all around the brain is still decreasing--therefore eliminating unnecessary connections and improving the brain functions--at age 20. For further proof, we can examine specific brain regions that are directly related to criminal behavior. The amygdala mediates emotions, processes fear, and tries to influence one's behavior based on their feelings. The prefrontal cortex helps with impulse control. During emotion regulation, when emotions want to control your actions, there are connections between the amygdala and PFC. The study done by Gee and other researchers showed that as age increased, functional connectivity between these two regions became increasingly more negative. These negative connections imply actions that are not solely based on emotions. This is an important piece of evidence for when brains should be considered mature; youth, including 25-year-olds, seem to be more likely to act on emotions than adults do. We also can look at diffusion tensor imaging to further endorse the idea of 18- yearold brains not being mature. Using the measurement of average water movement across the brain, DTI helps scientists understand the number of axons in a brain region. This method helped Swartz show that as age increases, there are less barriers between the amygdala and PFC and connections that can inhibit activity--e.g., Emotions regulating 
behavior--are more efficient. This study was done for people up to 20 and maintained that an 18 -year-old brain is not done maturing.

\section{Conclusion and Implications}

The scientific evidence showing that at 18 most brains are not done developing is clear. The ethical implications of using this science in policy making are large. Adult prison is a place meant for punishment, not rehabilitation. However, people who lack impulse control deserve to be in a place focusing on bettering themselves as opposed to being punished. In adult prison, 18-25-year-olds are the most likely to be abused in jail. There is also data showing that recidivism rates for this age group is very high. This may be because they are in the wrong environment. They should be in an environment that is developed for brains who are not mature: juvenile detention centers.

\section{Future Research}

The data that was included in this paper encompass different age groups; some show the brain maturity of 5-20-yearolds, others 18-24-year-olds. However, this prevalent ambiguity in brain development data suggests that there should be no clear cut off of when someone is no longer a juvenile. The brain is constantly developing and at different rates for different people. Therefore, I suggest that the decision for whether an offender should be tried as an adult or a juvenile be personalized (but anyone under 18 always be tried as a juvenile). Ideally, this would look like conducting brain scans to identify the amount of gray matter and connections between the brain. However, this is economically unrealistic. Instead, in a situation where someone is in the age group of 18-24-year old's, the judge and jury should analyze past behavior, the nature of the offense, and relationships. For example, interviewing one's parents can clue us in on whether they have trouble controlling their emotions. If they are known to be constantly at heightened feelings and reflect this in their actions, it is fair to assume that their impulse control is not at its full potential. The situation and degree of the crime must be taken into account as well. If someone hurts someone after an argument, this is more of a reaction to their emotions as opposed to someone hurting a stranger with no prior interaction. In simpler terms, for cases of 18-24-year-olds, judges should look at them case-by-case, using neuroscience and the history of the offender, to designate whether it can be tried in juvenile or adult court.

\section{Limitations}

While researching for this paper, there came many faults in current data. There is a lack of data that maps the brain in ages of 18-25. A lot of data either shows toddlers to teenagers or elderly adults Not a lot of data showcases the changing of the brain in this middle period of being a teen and an adult. I propose there needs to be more research done on how the brain develops during this age period of 18-25. Past data--although limited--has shown that the brain is not done maturing at 18 . Therefore, it is cruel to group 18-year-olds and older in a group filled with adults who are more mature and developed.

\section{Acknowledgments}

I would like to thank my mentor, Julian Day-Cooney, for his continued support and encouragement in helping me with this paper. From the beginning of my research, he was a constant guide and inspiration in working on this topic. 


\section{References}

[1] Kristin C. Thompson and Richard J. Morris, Juvenile Delinquency and Disability, Advancing Responsible Adolescent Development (Cham: Springer International Publishing, 2016), https://doi.org/10.1007/978-3-31929343-1.

[2] Samuel Lorenzo Knapp, The Life of Thomas Eddy: Comprising an Extensive Correspondence with Many of the Most Distinguished Philosophers and Philanthropists of This and Other Countries (Conner \& Cooke, 1834).

[3] Bradford Kinney Peirce, A Half Century with Juvenile Delinquents: Or, The New York House of Refuge and Its Times (D. Appleton, 1869).

[4] Anne Meis Knupfer, Reform and Resistance: Gender, Delinquency, and America’s First Juvenile Court (Psychology Press, 2001).

[5] Heyang Julie Kae, "Juvenile States: A Genealogy of Race, Gender and Delinquency in U.S. Culture, 1899-1967" (Thesis, 2014), https://digital.lib.washington.edu:443/researchworks/handle/1773/26694.

[6] PAUL ALLEN BECK and M. KENT JENNINGS, "LOWERING THE VOTING AGE: THE CASE OF THE RELUCTANT ELECTORATE*,” Public Opinion Quarterly 33, no. 3 (January 1, 1969): 370-79, https://doi.org/10.1086/267720.

[7] Neelum Arya, "Jailing Juveniles: The Dangers of Incarcerating Youth in Adult Jails in America," November 1, 2007.

[8] Vinnie Giordano, "Florida Has Work to Do to Treat African American Youth Fairly," Juvenile Justice Information Exchange, December 4, 2019, https://jie.org/2019/12/04/florida-has-work- to-do-to-treat-africanamerican-youth-fairly/.

[9] Lisa S. Yun, “The United States Stands Alone: An International Consensus Against Juvenile Life without Parole Sentences," Southern California Interdisciplinary Law Journal 20 (2011 2010): 727.

[10] "Eighth Amendment," LII / Legal Information Institute, accessed March 8, 2021, https:/www.law.cornell.edu/constitution/eighth_amendment.

[11] Betsy J. Grey, Neuroscience and Emotional Harm in Tort Law: Rethinking the American Approach to FreeStanding Emotional Distress Claims, Law and Neuroscience (Oxford University Press), accessed March 14, 2021 , https:/oxford.universitypressscholarship.com/view/10.1093/acprof:oso/9780199599844.001.000 1/acprof9780199599844-chapter-12.

[12] Jay D Aronson, “Neuroscience and Juvenile Justice,” Akron Law Review 42 (2009): 15.

[13] Roper v. Simmons (Syllabus), 543 U.S. 551 (U.S. Supreme Court 2005).

[14] Atkins v. Virginia (Syllabus), 536 U.S. 304 (U.S. Supreme Court 2002).

[15] Roper v. Simmons, 543 U.S.

[16] "Roper v. Simmons Resource Page," Death Penalty Information Center, accessed March 8, 2021, https://deathpenaltyinfo.org/facts-and-research/united-states-supreme-court/significant- supreme-courtopinions/roper-v-simmons-resource-page.

[17] “Graham v. Florida, 560 U.S. 48 (2010)," Justia Law, accessed March 8, 2021, https://supreme.justia.com/cases/federal/us/560/48/.

[18] Mary E Berkheiser, "Death Is Not So Different After All: Graham v. Florida and the Court's 'Kids Are Different' Eighth Amendment Jurisprudence," Vermont Law Review 36 (n.d.): 63.

[19] Terrance Jamar Graham, "Supreme Court of the United States,” n.d., 54.

[20] Justice Kennedy, Graham v. Florida ( Justice Kennedy , Opinion of the Court ), U.S. (U.S. Supreme Court 2010).

[21] "Walking the Line: Tracing the Science of Miller v. Alabama in State Appellate Opinions | Syracuse Journal of Law \& Civic Engagement," accessed March 8, 2021, https://slace.syr.edu/walking-the-line-tracing-the-science-ofmilner-v-alabama-in-state-appellate- opinions/. 
[22] “Miller v. Alabama, 567 U.S. 460 (2012)," Justia Law, accessed March 8, 2021, https://supreme.justia.com/cases/federal/us/567/460/.j

[23] “United States v. Tsarnaev, No. 16-6001 (1st Cir. 2020)," Justia Law, accessed March 8, 2021, https://law.justia.com/cases/federal/appellate-courts/ca1/16-6001/16-6001-2020-07- 31.html.

[24] "United States v. Tsarnaev, No. 16-6001 (1st Cir. 2020)."

[25] J Arnett, “Reckless Behavior in Adolescence: A Developmental Perspective,” Developmental Review 12, no. 4 (December 1992): 339-73, https://doi.org/10.1016/0273-2297(92)90013-R.

[26] Graham, "Supreme Court of the United States."

[27] Graham.

[28] D. Knoch and E. Fehr, "Resisting the Power of Temptations: The Right Prefrontal Cortex and Self-Control," Annals of the New York Academy of Sciences 1104, no. 1 (April 13, 2007): 123- 34, https://doi.org/10.1196/annals.1390.004.

[29] "Impulse Control Comes Late for Teens," Futurity (blog), October 12, 2009, https://www.futurity.org/impulsecontrol-comes-late-for-teens/.

[30] "Impulse Control Comes Late for Teens."

[31] Luna, Beatriz, Aarthi Padmanabhan, and Kirsten O’Hearn. "What Has FMRI Told Us about the Development of Cognitive Control through Adolescence?” Brain and Cognition 72, no. 1 (February 2010): 101-13. https://doi.org/10.1016/j.bandc.2009.08.005

[32] Sakai, Jill. "Core Concept: How Synaptic Pruning Shapes Neural Wiring during Development and, Possibly, in Disease." Proceedings of the National Academy of Sciences 117, no. 28 (July 14, 2020): 16096-99. https://doi.org/10.1073/pnas.2010281117.

[33] Anthony A. Mercadante and Prasanna Tadi, "Neuroanatomy, Gray Matter," in StatPearls (Treasure Island (FL): StatPearls Publishing, 2021), http://www.ncbi.nlm.nih.gov/books/NBK553239/.

[34] Efstathios D. Gennatas et al., "Age-Related Effects and Sex Differences in Gray Matter Density, Volume, Mass, and Cortical Thickness from Childhood to Young Adulthood," The Journal of Neuroscience 37, no. 20 (May 17, 2017): 5065-73, https://doi.org/10.1523/JNEUROSCI.3550-16.2017.

[35] Sang Soo Cho et al., "Morphometric Correlation of Impulsivity in Medial Prefrontal Cortex," Brain Topography 26, no. 3 (July 2013): 479-87, https://doi.org/10.1007/s10548-012-0270-x.

[36] “Teenage Brain Development and Criminal Behavior," Crime Traveller (blog), June 16, 2015 , https:/www.crimetraveller.org/2015/06/teenage-brain-development/.

[37] "White Matter in Learning, Cognition and Psychiatric Disorders - ScienceDirect," accessed March 14, 2021, https://www.sciencedirect.com/science/article/abs/pii/S016622360800132X.

[38] Christian K. Tamnes et al., "Brain Maturation in Adolescence and Young Adulthood: Regional Age-Related Changes in Cortical Thickness and White Matter Volume and Microstructure," Cerebral Cortex 20, no. 3 (March 2010): 534-48, https://doi.org/10.1093/cercor/bhp118.

[39] Lauren J. O’Donnell and Carl-Fredrik Westin, "An Introduction to Diffusion Tensor Image Analysis," Neurosurgery Clinics of North America 22, no. 2 (April 2011): 185-viii, https://doi.org/10.1016/j.nec.2010.12.004. [40] Johnna R. Swartz et al., "Age-Related Changes in the Structure and Function of Prefrontal Cortex-Amygdala Circuitry in Children and Adolescents: A Multi-Modal Imaging Approach," NeuroImage 86 (February 2014): 21220, https://doi.org/10.1016/j.neuroimage.2013.08.018.

[41] Ralph Adolphs, "The Human Amygdala and Emotion,” The Neuroscientist 5, no. 2 (March 1, 1999): 125-37, https://doi.org/10.1177/107385849900500216.

[42] R. Adolphs et al., "Fear and the Human Amygdala," The Journal of Neuroscience: The Official Journal of the Society for Neuroscience 15, no. 9 (September 1995): 5879-91.

[43] Knoch and Fehr, "Resisting the Power of Temptations." 
[44] Dylan G. Gee et al., "A Developmental Shift from Positive to Negative Connectivity in Human AmygdalaPrefrontal Circuitry," The Journal of Neuroscience 33, no. 10 (March 6, 2013): 4584-93, https://doi.org/10.1523/JNEUROSCI.3446-12.2013.

[45] Swartz et al., "Age-Related Changes in the Structure and Function of Prefrontal Cortex- Amygdala Circuitry in Children and Adolescents."

[46] Sarah J. Banks et al., "Amygdala-Frontal Connectivity during Emotion Regulation," Social Cognitive and Affective Neuroscience 2, no. 4 (December 1, 2007): 303-12, https://doi.org/10.1093/scan/nsm029.

[47] Gee et al., "A Developmental Shift from Positive to Negative Connectivity in Human Amygdala-Prefrontal Circuitry."

[48] Jill X. O'Reilly et al., "Tools of the Trade: Psychophysiological Interactions and Functional Connectivity," Social Cognitive and Affective Neuroscience 7, no. 5 (June 2012): 604-9, https://doi.org/10.1093/scan/nss055.

[49] Christine E Fitch, "Emerging Adulthood and the Criminal Justice System: \#Brainnotfullycooked \#Can’tadultyet \#Yolo," SANTA CLARA LAW REVIEW 58 (n.d.): 20.

[50] Fitch.

[51] Mark W. Lipsey et al., "Effective Intervention for Serious Juvenile Offenders.: (306462003- 001)" (American Psychological Association, 2000), https://doi.org/10.1037/e306462003-001. [52] "KEY FACTS: YOUTH IN THE JUSTICE SYSTEM,” n.d., 13. 